\title{
PEMBERIAN OBAT PENCEGAHAN SECARA MASSAL (POPM) DALAM PENANGGULANGAN FILARIASIS DI KABUPATEN OGAN KOMERING ILIR, PROVINSI SUMATERA SELATAN, TAHUN 2013 - 2017
}

\author{
Rizki Nurmaliani ${ }^{1^{*}}$, Maya Arisanti ${ }^{1}$ \\ ${ }^{1}$ Balai Penelitian dan Pengembangan Kesehatan Baturaja \\ JI. A.Yani KM.7 Kemelak Baturaja, 32111, Kabupaten Ogan Komering Ulu, Sumatera Selatan, Indonesia
}

\begin{abstract}
Filariasis is one of the health problems in Ogan Komering Ilir (OKI) Regency. The implementation of countermeasures for filariasis is carried out by both the central and regional governments by involving the participation of the community. One of them is by breaking the chain of transmission through the Mass Drug Administration (MDA). Mass Drug Administration is implemented by administering drugs that aim to kill microfilariae simultaneously to all target populations. From 2013 to 2017, Health District of OKI carried out MDA for eliminating filariasis. This paper aims to see an overview of the MDA implementation in OKI Regency for five years. The data used are secondary data from the Health District Office of OKI Regency and analyzed descriptively. From the data collected, the results show that the MDA was carried out simultaneously in all villages in OKI. Coverage of MDA in the target groups from 2013 to 2017 were $90 \%, 91 \%, 91 \%, 94 \%$, and $95 \%$ respectively. This figure has reached the minimum target of $65 \%$ which has been set as the target of elimination of filariasis. In addition, coverage rates continue to increase every year. Thus, it can be concluded that the coverage of filariasis MDA implementation in OKI Regency is good.
\end{abstract}

Keywords: Filariasis, MDA, OKI Regency.

\section{MASS DRUG ADMINISTRATION (MDA) IN FILARIASIS ELIMINATION IN OGAN KOMERING ILIR REGENCY, SOUTH SUMATRA PROVINCE, 2013 - 2017}

\begin{abstract}
Abstrak
Filariasis merupakan salah satu masalah kesehatan di Kabupaten Ogan Komering Ilir (OKI). Penyelenggaraan penanggulangan filariasis dilaksanakan baik oleh pemerintah pusat maupun pemerintah daerah dengan melibatkan peran serta dari masyarakat. Salah satunya adalah dengan memutus rantai penularan melalui Pemberian Obat Pencegahan secara Massal (POPM) filariasis. POPM dilaksanakan melalui pemberian obat yang bertujuan untuk mematikan mikrofilaria secara serentak kepada semua penduduk sasaran. Sejak tahun 2013 hingga tahun 2017, pemerintah Kabupaten OKI melaksanakan kegiatan POPM untuk eliminasi filariasis. Tulisan ini bertujuan untuk melihat gambaran pelaksanaan POPM di Kabupaten OKI selama lima tahun. Data yang digunakan adalah data sekunder dari Dinas Kesehatan Kabupaten OKI dan dianalisis secara deskriptif. Dari data yang telah dikumpulkan didapatkan hasil bahwa pelaksanaan POPM dilakukan secara serentak pada semua desa yang ada di wilayah Kabupaten OKI. Cakupan POPM filariasis pada kelompok sasaran tahun 2013 hingga tahun 2017 berturut-turut adalah 90\%, 91\%, 91\%, 94\%, dan 95\%. Angka ini sudah mencapai target minimal $65 \%$ yang telah ditetapkan sebagai target eliminasi filariasis. Selain itu, angka cakupan terus mengalami peningkatan setiap tahunnya. Dengan demikian, dapat disimpulkan bahwa cakupan pelaksanaan POPM filariasis di Kabupaten OKI sudah baik.
\end{abstract}

Kata Kunci : Filariasis, POPM, Kabupaten OKI. 
*Alamat korespondensi penulis pertama: e-mail: rizkinurmaliani@yahoo.co.id; Telp: (0735) 325303

\section{PENDAHULUAN}

Filariasis atau yang dikenal juga dengan kaki gajah merupakan salah satu penyakit tropis terabaikan (neglected tropical disease) yang masih menjadi masalah kesehatan sampai saat ini. ${ }^{1,2}$ Filariasis disebabkan oleh cacing filaria dan ditularkan melalui gigitan nyamuk. ${ }^{3}$ Ada tiga jenis spesies cacing filaria penyebab filariasis di Indonesia, yaitu Wuchereria bancrofti, Brugia malayi, dan Brugia timori. Dari ketiga jenis cacing filaria ini, yang paling banyak menginfeksi masyarakat Indonesia adalah Brugia malayi. ${ }^{4}$

Infeksi penyakit ini tidak menunjukkan adanya gejala pada sebagian besar kasus. Larva cacing filaria yang masuk ke dalam tubuh tumbuh menjadi cacing dewasa dan menetap di jaringan limfe menyebabkan kerusakan tersembunyi pada sistem limfatik (getah bening) selama bertahun-tahun dan menyebabkan pembengkakan di kaki, tungkai, payudara, lengan, dan organ genital. ${ }^{4,5}$ Filariasis tidak menyebabkan kematian, akan tetapi penyakit ini dapat menyebabkan kecacatan permanen dan disabilitas (keterbatasan) yang dapat berdampak pada produktivitas pada penderitanya. ${ }^{4}$ Selain itu, penderita juga dapat mengalami stres atau dampak psikologis oleh stigma masyarakat sekitar terkait penularan penyakit sehingga penderita dijauhi atau dikucilkan oleh masyarakat di sekitar tempat tinggal. ${ }^{6}$

World Health Organization (WHO) menyatakan bahwa sampai pada tahun 2018 terdapat 856 juta penduduk di 52 negara berisiko untuk tertular filariasis dan diperkirakan sebagian kasus berasal dari Asia Tenggara. ${ }^{4}$ Tahun 2018, Indonesia melaporkan 10.681 kasus filariasis yang tersebar di 34 provinsi. Angka ini menurun jika dibandingkan dengan kasus pada tahun 2017, yaitu 12.677 kasus. $^{7}$ Lima provinsi dengan kasus kronis filariasis terbanyak pada tahun 2017 dan 2018 adalah Papua, Nusa Tenggara Timur, Jawa Barat, Papua Barat, dan Aceh. Terdapat 236 kabupaten/kota yang termasuk dalam daerah endemis filariasis pada 28 provinsi di Indonesia. 5,7

Tahun 2000, WHO meluncurkan kesepakatan global "Global Programme to Eliminate Lymphatic Filariasis (GPELF)" untuk mengeliminasi filariasis pada tahun 2020. Tujuan utama dari GELPF ini adalah untuk menghentikan transmisi filariasis melalui pemberian obat secara massal. ${ }^{1} \mathrm{Di}$ Indonesia, eliminasi filariasis secara global dicanangkan sejak tahun 2002.6,8 Program eliminasi filariasis bertujuan untuk menurunkan angka mikrofilaria menjadi kurang dari $1 \%$ di setiap kabupaten/kota sehingga filariasis tidak menjadi masalah kesehatan masyarakat di Indonesia pada tahun 2020. Pelaksanaan penanggulangan filariasis sebagai bagian dari eliminasi filariasis global dilakukan melalui dua pilar kegiatan yang salah satunya adalah memutuskan mata rantai penularan filariasis dengan POPM filariasis di daerah endemis sekali setahun selama lima tahun berturutturut. Jumlah kabupaten/kota yang masih melaksanakan POPM filariasis di Indonesia pada tahun 2017 sebanyak 152 kabupaten/kota. ${ }^{5}$

Sumatera Selatan merupakan salah satu provinsi yang melaksanakan POPM filariasis. Sampai tahun 2017, jumlah kasus kronis filariasis di Sumatera Selatan adalah 200 kasus dan terdapat sembilan kabupaten/kota endemis filariasis. Dari 9 kabupaten/kota endemis ini, 8 kabupaten/kota $\quad(88,9 \%) \quad$ masih melaksanakan POPM filariasis pada tahun $2017,{ }^{5}$ salah satunya adalah Kabupaten Ogan Komering llir (OKI). POPM filariasis di Kabupaten OKI mulai dilaksanakan sejak tahun 2013 dan pada tahun 2017 sudah memasuki tahun ke lima POPM. ${ }^{9}$ Tulisan ini bertujuan untuk mendapatkan gambaran pelaksanaan POPM di Kabupaten OKI selama lima tahun. 


\section{METODE}

Data yang digunakan dalam tulisan ini merupakan data sekunder berupa laporan POPM di Kabupaten OKI pada tahun 2013 hingga tahun 2017 yang diperoleh dari Dinas Kesehatan Kabupaten OKI. Selanjutnya data dianalisis secara deskriptif untuk melihat cakupan pemberian obat filariasis .

Cakupan POPM dilihat berdasarkan pada perhitungan persentase jumlah penduduk minum obat dari jumlah penduduk total dan persentase jumlah penduduk minum obat dari jumlah penduduk sasaran.

$\begin{aligned} & \text { Angka } \\ & \text { cakupan dari }\end{aligned}=\frac{\text { Jumlah penduduk minum obat }}{\text { Jumlahpenduduk total }} \times 100 \%$ penduduk

total
Angka
cakupan dari $=\frac{\text { Jumlah penduduk minum obat }}{\text { Jumlah penduduk sasaran }} \times 100 \%$
penduduk
sasaran

\section{HASIL}

Berdasarkan laporan jumlah kasus kronis filariasis Dinas Kesehatan Kabupaten OKI tahun 2017 diketahui bahwa terdapat 8 kasus kronis (1 kasus telah meninggal dunia). Kasus kronis ini tersebar pada lima kecamatan yaitu Kecamatan Kayuagung, Sp. Padang, Teluk Gelam, Tanjung Lubuk, dan Lempuing. Kasus kronis ini didasarkan pada penemuan kasus saat pelaksanaan POPM. Sebanyak 6 kasus ditemukan pada POPM putaran pertama tahun 2013 dan masing-masing 1 kasus ditemukan pada saat POPM tahun 2015 dan tahun 2017.

Tabel 1. Kasus Kronis Filariasis di Kabupaten OKI Tahun 2013 s.d. 2017

\begin{tabular}{cllll}
\hline \multirow{2}{*}{ No. } & & \multicolumn{2}{c}{ Jumlah Kasus } & \multirow{2}{*}{ Total } \\
\cline { 3 - 4 } & & $\mathrm{L}$ & $\mathrm{P}$ & \\
\hline 1 & Kayuagung & 1 & 0 & 1 \\
2 & Sp. Padang & 1 & 0 & 1 \\
3 & Teluk Gelam & 1 & 0 & 1 \\
4 & Tanjung Lubuk & 2 & 1 & 3 \\
5 & Lempuing & 2 & 0 & 2 \\
\hline & & 7 & 1 & 8 \\
\hline
\end{tabular}

Sumber : Dinas Kesehatan Kabupaten OKI

Penanggulangan filariasis melalui POPM mulai dilaksanakan di Kabupaten OKI sejak tahun 2013. POPM filariasis dilakukan pada semua desa yang ada di Kabupaten OKI selama lima tahun berturut-turut sampai dengan tahun 2017.

Tabel 2. Cakupan Pemberian Obat pada POPM Filariasis di Kabupaten OKI Tahun 2013 s.d. 2017

\begin{tabular}{ccccc}
\hline No. & Tahun & Jumlah Puskesmas & Jumlah Desa & \% Desa Diberi Obat \\
\hline 1 & 2013 & 29 & 321 & 100 \\
2 & 2014 & 29 & 321 & 100 \\
3 & 2015 & 29 & 321 & 100 \\
4 & 2016 & 29 & 323 & 100 \\
5 & 2017 & 30 & 323 & 100 \\
\hline
\end{tabular}

Sumber : Laporan Cakupan Pelaksanaan POPM Dinas Kesehatan Kabupaten OKI 
Obat yang dibagikan kepada kelompok sasaran dalam pelaksanaan POPM filariasis adalah Dietylcarbamazine (DEC) kombinasi
Albendazole. Cakupan POPM filariasis selama lima tahun dapat dilihat pada Gambar 1.

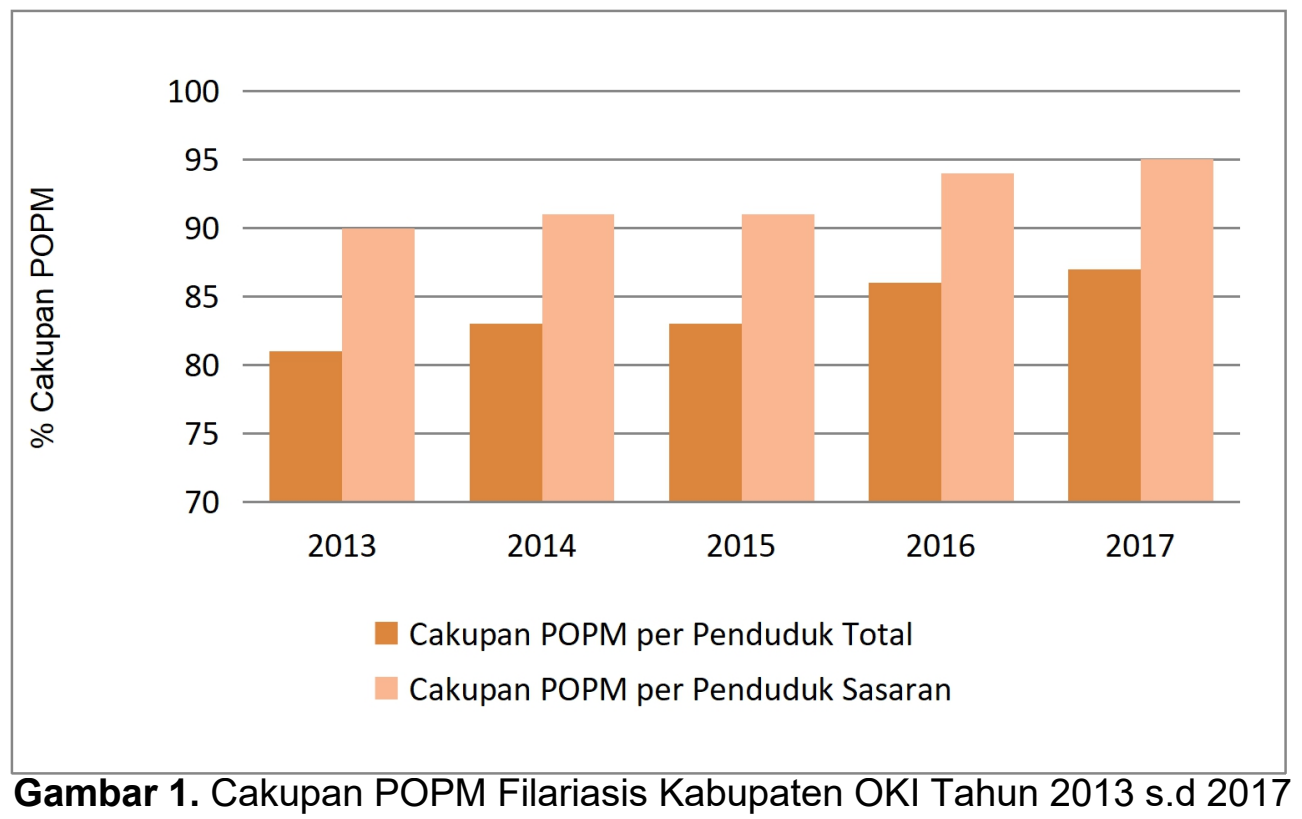

Pada tahun 2013, cakupan POPM filariasis Kabupaten OKI adalah $81 \%$ dari jumlah penduduk total atau $90 \%$ dari jumlah penduduk sasaran, sedangkan pada tahun 2017, cakupan POPM filariasis Kabupaten OKI mencapai $87 \%$ dari jumlah penduduk total atau $95 \%$ dari jumlah penduduk sasaran.

\section{BAHASAN}

Kasus filariasis di Kabupaten OKI banyak terjadi pada laki-laki dibandingkan perempuan. Penelitian Veridiana di Kabupaten Mamuju Utara Sulawesi Barat menunjukkan bahwa sebagian besar penderita filariasis adalah laki-laki. ${ }^{10}$ Penelitian Juriastuti di Kelurahan Jati Sampurna juga menunjukkan hasil bahwa salah satu karakteristik individu yang memiliki hubungan yang signifikan dengan kejadian filariasis adalah jenis kelamin. Dalam penelitian ini juga diketahui bahwa laki-laki memiliki risko 4,7 kali lebih besar dibandingkan dengan perempuan. ${ }^{11}$ Lebih besarnya risiko laki-laki untuk terkena filariasis disebabkan karena laki-laki memiiki kesempatan yang lebih banyak untuk terpapar. $^{12}$ Laki-laki lebih sering memiliki aktivitas di luar rumah pada malam hari jika dibandingkan dengan perempuan. Selain itu, sehubungan dengan mencari nafkah, laki- laki memiliki mobilitas yang lebih tinggi sehingga kemungkinan untuk kontak dengan vektor filariasis menjadi lebih besar juga. ${ }^{10,11,13}$

Penularan filariasis dapat diatasi atau bahkan dihentikan apabila jumlah mikrofilaria di masyarakat berhasil diturunkan. Walaupun terdapat nyamuk sebagai vektor, gigitannya tidak akan menyebabkan penularan filariasis apabila jumlah mikrofilaria di dalam darah penderita sangat rendah. ${ }^{14}$ Oleh karena itu, POPM menjadi salah satu upaya pemutusan rantai penularan dalam eliminasi filariasis. Pemberian obat dilakukan untuk mematikan mikrofilaria secara serentak kepada semua penduduk sasaran usia 2-70 tahun di wilayah endemis filariasis, dilaksanakan sekali setiap tahunnya paling sedikit selama lima tahun. ${ }^{4}$ Obat yang digunakan adalah dosis tunggal DEC $6 \mathrm{mg} / \mathrm{kgBB}$ dan dikombinasikan dengan Albendazole 400 mg. $5,15,16$

Pembagian kombinasi obat DEC dan Albendazole secara serentak kepada semua penduduk di Kabupaten OKI dalam rangka pelaksanaan POPM filariasis mulai dilaksanakan pada tahun 2013. Sejak awal, angka penduduk minum obat mencapai angka lebih dari $80 \%$ baik dari total jumlah penduduk maupun total jumlah penduduk 
sasaran. Selama lima tahun pelaksanaan POPM filariasis, jumlah penduduk minum obat ini mengalami peningkatan dari tahun ke tahun. Dari angka ini dapat dikatakan bahwa cakupan POPM di Kabupaten OKI sudah baik. Penelitian yang dilakukan oleh Solikha dan Adi di Demak menunjukkan hasil yang serupa, yaitu, angka cakupan POPM filariasis lebih dari $85 \% .{ }^{17}$ Hasil berbeda ditemukan pada penelitian Habibah dan Sungkar, hasil penelitian yang di lakukan di Kabupaten Sumba Barat Daya ini menunjukkan bahwa cakupan filariasis masih sangat rendah yaitu kurang dari $3 \%$. Pada target eliminasi filariasis disebutkan bahwa untuk memutus rantai penularan, minimal angka cakupan POPM yang harus dicapai adalah $65 \%$ dari jumlah penduduk sasaran dan $85 \%$ dari jumlah penduduk total. ${ }^{18}$

Cakupan POPM yang baik dapat menjadi faktor pendukung dalam keberhasilan eliminasi filariasis, sebaliknya cakupan yang rendah dapat menjadi penghambat dalam eliminasi filariasis. ${ }^{19}$ Penelitian Reni menunjukkan bahwa POPM filariasis yang dilakukan di Kabupaten Banyuasin dapat menurunkan angka prevalensi mikrofilaria menjadi $<1 \%{ }^{20}$ Penelitian yang dilakukan oleh Setyaningtyas di Kabupaten Tanah Bumbu juga menunjukkan terjadinya penurunan mikrofilaria rate setelah dilakukan POPM filariasis dan keberhasilan penurunan angka ini karena angka penduduk minum obat yang tinggi. ${ }^{14}$

Banyaknya jumlah penduduk minum obat atau besarnya angka cakupan POPM tidak terlepas dari penerimaan/kepatuhan masyarakat terhadap kegiatan POPM itu sendiri. ${ }^{21}$ Cakupan POPM akan tinggi jika masyarakat memiliki pengetahuan, sikap, dan perilaku yang baik tentang POPM filariasis. ${ }^{18}$ Masyarakat yang memiliki pengetahuan yang baik tentang manfaat dari pengobatan massal akan memiliki kesadaran dan sikap yang positif sehingga terdorong secara sukarela untuk berpartisipasi dalam kegiatan POPM.6,22 Penelitian Ambarita menunjukkan bahwa ketidaktahuan responden terhadap kegiatan pengobatan penyakit kaki gajah di daerahnya dan kurangnya sosialisasi, berhubungan secara bermakna dengan kesediaan minum obat. ${ }^{23}$ Tenaga kesehatan dan kader juga berperan penting dalam keberhasilan/capaian angka cakupan POPM. ${ }^{21}$ Tenaga kesehatan/kader berperan dalam meningkatkan pengetahuan masyarakat dan juga pengawasan atau kunjungan untuk memastikan obat yang diberikan tidak hanya diterima, tetapi juga diminum. Tenaga kesehatan dan kader yang aktif melakukan sosialisasi dan pemantauan dalam kegiatan POPM akan meningkatkan penerimaan dan keberhasilan eliminasi filariasis melalui POPM di masyarakat. ${ }^{22,24}$ Hasil penelitian Ipa menunjukkan bahwa keberadaan kader dapat meningkatkan cakupan POPM filariasis. Kader dapat berperan memotivasi masyarakat untuk memahami manfaat POPM sehingga bersedia untuk minum obat. $^{25,26}$

\section{KESIMPULAN}

POPM filariasis yang telah dilakukan sejak tahun 2013 hingga tahun 2017 di Kabupaten OKI berjalan dengan baik. Selama lima tahun pelaksanaannya, cakupan POPM filariasis telah melebihi target minimal yang telah ditetapkan untuk eliminasi filariasis. Hal ini dapat dilihat dari besarnya jumlah penduduk minum obat yang melebihi angka $80 \%$ baik dari total jumlah penduduk maupun jumlah penduduk sasaran.

\section{SARAN}

Keberhasilan eliminasi filariasis dapat dicapai melalui baiknya angka cakupan POPM filariasis yang didukung pula oleh baiknya pengendalian vektor. Untuk itu, upaya pencegahan atau perlindungan dari gigitan nyamuk dan upaya penyehatan lingkungan harus tetap dilakukan.

\section{KONTRIBUSI PENULIS}

RN dan MA sebagai kontributor utama dalam penulisan ini yang bertanggung jawab pada konsep, analisis data, metodelogi, mengkaji hasil, penelusuran referensi, kesimpulan dan saran.

\section{UCAPAN TERIMA KASIH}

Terima kasih kepada Kepala Dinas Kesehatan Kabupaten OKI beserta staf, 
Kepala Balai Litbang Kesehatan Baturaja yang telah membantu penulisan artikel ini.

\section{DAFTAR PUSTAKA}

1 World Health Organization (WHO). Lymphatic Filariasis A Handbook for National Elimination Programmes. 2013.

2 Sitorus, H., Ambarita, L. P., Arisanti, M., \& Manalu, H. S. Pengetahuan tokoh masyarakat dan kader kesehatan tentang program eliminasi filariasis limfatik di Kecamatan Pemayung Kabupaten Batanghari Provinsi Jambi. ASPIRATOR-Journal of Vector-borne Disease Studies. 2016;8(2): 93-100.

3 Elytha, F. Transmission Assessment Survey Sebagai Salah Satu Langkah Penentuan Eliminasi Filariasis. Jurnal Kesehatan Masyarakat Andalas. 2014;8(2):85-92.

4 Harpini, Annisa. Infodatin : Menuju Indonesia Bebas Filariasis. Jakarta : Kementerian Kesehatan. 2018.

5 Kementerian Kesehatan. Profil Kesehatan Indonesia Tahun 2017. Jakarta : Kementerian Kesehatan. 2018.

6 Meliyanie, G., \& Andiarsa, D. Program Eliminasi Lymphatic Filariasis di Indonesia. JHECDs: Journal of Health Epidemiology and Communicable Diseases. 2017;3(2):63-70.

7 Kementerian Kesehatan. Profil Kesehatan Indonesia Tahun 2018. Jakarta : Kementerian Kesehatan. 2019.

8 Sopi, I. I. P., \& Adnyana, N. W. D. Cakupan Pengobatan Massal Filariasis di Kabupaten Sumba Barat Daya Tahun 2011. Jurnal Ekologi Kesehatan. 2013;12(1):19-24.

9 Dinas kesehatan Kab. Ogan Komering Ilir (OKI). Laporan Cakupan Pelaksanaan POPM Filariasis Tahun 2013-2017.

10 Veridiana, N. N., Chadijah, S., Ningsi. Pengetahuan, Sikap dan Perilaku Masyarakat terhadap Filariasis di Kabupaten Mamuju Utara, Sulawesi Barat. Buletin Penelitian Kesehatan. 2015; 43(1):47-54.

11 Juriastuti, P. M. K. M., Kartika, M., Djaja, I. M., \& Susanna, D. Faktor Risiko Kejadian Filariasis di Kelurahan Jati
Sampurna. Makara Kesehatan. 2010;14(1):31-36.

12 Masrizal, M. Penyakit Filariasis. Jurnal Kesehatan Masyarakat Andalas. 2012;7(1):32-38.

13 Mutiara, H., Anindita, A. Filariasis: Pencegahan Terkait Faktor Risiko. Jurnal Majority. 2016;5(3):11-16.

14 Setyaningtyas, D. E., Yuana, W. T., \& Rahayu, N. Keberhasilan Pengobatan Massal Filariasis di Kecamatan Kusan Hulu Kabupaten Tanah Bumbu Provinsi Kalimantan Selatan. BALABA: Jurnal Litbang Pengendalian Penyakit Bersumber Binatang Banjarnegara. 2017;13(2):133-142.

15 Patanduk, Y., Yunarko, R., \& Mading, M. Penerimaan Masyarakat dan Cakupan Pengobatan Massal Filariasis di Kecamatan Kodi Balaghar. Buletin Penelitian Sistem Kesehatan. 2016;19(2):157-163.

16 Purwantyastuti. Pemberian Obat Massal Pencegahan (POMP) Filariasis. Buletin Jendela Epidemiologi. 2010;1:15-19

17 Solikha I, Adi MS. Filariasis Distribution And Coverage Of Mass Drug Administration. Jurnal Berkala Epidemiologi. 2019 Sep 30;7(3):180-8.

18 Habibah, Z., \& Sungkar, S. Cakupan Pemberian Obat Pencegahan Massal Filariasis di Kabupaten Sumba Barat Daya Tahun 2012-2013. Jurnal Kedokteran Indonesia. 2015;3(3):199203

19 Santoso, S., Cahyaningrum, S. ReTransmission Assessment Survey Filariasis Pasca Pengobatan Massal di Kabupaten Agam, Provinsi Sumatera Barat Tahun 2016. BALABA: Jurnal Litbang Pengendalian Penyakit Bersumber Binatang Banjarnegara, 2017;13(2):143-152.

20 Oktarina, R., Santoso, S., \& Taviv, Y. Gambaran Angka Prevalensi Mikrofilaria di Kabupaten Banyuasin Pasca Pengobatan Massal Tahap III. BALABA: Jurnal Litbang Pengendalian Penyakit Bersumber Binatang Banjarnegara. 2017;13(1):11-20.

21 Ipa, M., dkk. Kinerja Kader Kesehatan dalam Pengobatan Massal Filariasis di Kecamatan Cibeureum dan Cibingbin 
Kabupaten Kuningan. Media Litbangkes. 2018;28(1):1-8.

22 Juhairiyah, J., dkk. Kepatuhan Masyarakat Minum Obat Pencegah Massal Filariasis (Kaki Gajah): Studi Kasus Desa Bilas, Kabupaten Tabalong. Jurnal Vektor Penyakit. 2019;13(1):4958.

23 Ambarita, L. P. Perilaku Masyarakat Terkait Penyakit Kaki Gajah dan Program Pengobatan Massal di Kecamatan Pemayung Kabupaten Batanghari, Jambi. Media Penelitian dan Pengembangan Kesehatan. 2014;24(4):191 - 198.

24 Lobo, V., Bulu, A. K., Noshirma, M. Pemberian Obat Massal Pencegah Filariasis di Desa Mbilur Pangadu Kabupaten Sumba Tengah. Media Penelitian dan Pengembangan Kesehatan. 2018;28(3):167-174.

25 Ipa, M., Astuti, E. P., Hakim, L., Fuadzy, $\mathrm{H}$. Analisis cakupan obat massal pencegahan Filariasis di Kabupaten Bandung dengan pendekatan model sistem dinamik. BALABA: Jurnal Litbang Pengendalian Penyakit Bersumber Binatang Banjarnegara. 2016;12(1): 31-38.

26 Hayati, R., Fahrurazi, F. Determinan Kinerja Kader Filariasis di Kalimantan Selatan. Jurnal Publikasi Kesehatan Masyarakat Indonesia. 2018;.5(3):7680. 